\title{
RESEARCH
}

Open Access

\section{School-based gardening, cooking and nutrition intervention increased vegetable intake but did not reduce BMI: Texas sprouts - a cluster randomized controlled trial}

Jaimie N. Davis ${ }^{1 *}$, Adriana Pérez², Fiona M. Asigbee ${ }^{1}$, Matthew J. Landry', Sarvenaz Vandyousefi ${ }^{1}$, Reem Ghaddar ${ }^{1}$, Amy Hoover ${ }^{1}$, Matthew Jeans ${ }^{1}$, Katie Nikah', Brian Fischer², Stephen J. Pont ${ }^{3}$, Daphne Richards ${ }^{4}$,

Deanna M. Hoelscher ${ }^{5}$ and Alexandra E. Van Den Berg ${ }^{5}$

\begin{abstract}
Background: Although school garden programs have been shown to improve dietary behaviors, there has not been a cluster-randomized controlled trial (RCT) conducted to examine the effects of school garden programs on obesity or other health outcomes. The goal of this study was to evaluate the effects of a one-year school-based gardening, nutrition, and cooking intervention (called Texas Sprouts) on dietary intake, obesity outcomes, and blood pressure in elementary school children.
\end{abstract}

Methods: This study was a school-based cluster RCT with 16 elementary schools that were randomly assigned to either the Texas Sprouts intervention ( $n=8$ schools) or to control (delayed intervention, $\mathrm{n}=8$ schools). The intervention was one school year long ( 9 months) and consisted of: a) Garden Leadership Committee formation; b) a 0.25 -acre outdoor teaching garden; c) 18 student gardening, nutrition, and cooking lessons taught by trained educators throughout the school-year; and d) nine monthly parent lessons. The delayed intervention was implemented the following academic year and received the same protocol as the intervention arm. Child outcomes measured were anthropometrics (i.e., BMI parameters, waist circumference, and body fat percentage via bioelectrical impedance), blood pressure, and dietary intake (i.e., vegetable, fruit, and sugar sweetened beverages) via survey. Data were analyzed with complete cases and with imputations at random. Generalized weighted linear mixed models were used to test the intervention effects and to account for clustering effect of sampling by school.

* Correspondence: Jaimie.davis@austin.utexas.edu

'Department of Nutritional Sciences, University of Texas at Austin, 1400 Barbara Jordan Blvd, Austin, TX 78723, USA

Full list of author information is available at the end of the article

(c) The Author(s). 2021 Open Access This article is licensed under a Creative Commons Attribution 4.0 International License, which permits use, sharing, adaptation, distribution and reproduction in any medium or format, as long as you give appropriate credit to the original author(s) and the source, provide a link to the Creative Commons licence, and indicate if changes were made. The images or other third party material in this article are included in the article's Creative Commons licence, unless indicated otherwise in a credit line to the material. If material is not included in the article's Creative Commons licence and your intended use is not permitted by statutory regulation or exceeds the permitted use, you will need to obtain permission directly from the copyright holder. To view a copy of this licence, visit http://creativecommons.org/licenses/by/4.0/. The Creative Commons Public Domain Dedication waiver (http://creativecommons.org/publicdomain/zero/1.0/) applies to the data made available in this article, unless otherwise stated in a credit line to the data. 


\begin{abstract}
(Continued from previous page)
Results: A total of 3135 children were enrolled in the study (intervention $n=1412,45 \%$ ). Average age was 9.2 years, $64 \%$ Hispanic, 47\% male, and 69\% eligible for free and reduced lunch. The intervention compared to control resulted in increased vegetable intake ( $+0.48 \mathrm{vs} .+0.04$ frequency/day, $p=0.02)$. There were no effects of the intervention compared to control on fruit intake, sugar sweetened beverages, any of the obesity measures or blood pressure.

Conclusion: While this school-based gardening, nutrition, and cooking program did not reduce obesity markers or blood pressure, it did result in increased vegetable intake. It is possible that a longer and more sustained effect of increased vegetable intake is needed to lead to reductions in obesity markers and blood pressure.
\end{abstract}

Clinical trials number: NCT02668744.

Keywords: Gardening, Nutrition, Cooking intervention, Hispanic, Low-income, Obesity, Overweight, School-based

\section{Background}

Studies have consistently shown that increased fruit and vegetable (FV) intake can promote health, lower cardiovascular disease, type 2 diabetes, and some cancers [14]. Increased FV may play a role in reduced obesity in adults $[5,6]$, but the literature supporting this claim in children is unclear $[7,8]$. Children in the U.S. do not meet the recommended daily intake for FV, and intake is lowest in low-income and Hispanic populations [9]. Low-income Hispanic families are more likely to live in communities with limited access to healthy foods, often referred to as "food deserts" or "food swamps", and have less access to quality FV, and increased access to less healthful foods [10, 11]. High levels of acculturation by Hispanics to the dominant U.S. culture might also explain their decreased FV consumption, and increased consumption of unhealthy foods $[12,13]$. Further, prices of fresh FV have increased at a much faster rate than high fat/sugar foods [14]. Numerous studies have also shown that lack of FV exposure, preference, knowledge and self-efficacy is linked to lower FV intake in children [15-18]. Evidence-based interventions are needed to improve these psychosocial variables and increase FV access, availability, and intake, particularly in low-income populations.

School gardens have become a common health promotion strategy to increase FV intake in the U.S. In the past two decades, numerous studies have examined the effects of school gardens on psychosocial variables, FV intake, food literacy, and mental health in children [1924]. Several experimental studies $[25,26]$ have shown that gardening is linked to lower obesity levels in adults, however few studies have reported on the effects of gardening on obesity and related health measures in children [27]. We completed a pilot study in 2014 in which four schools $(\sim 4003$ rd-5th grade students) were randomly assigned to either a 12-week after-school gardening, nutrition, and cooking intervention (LA Sprouts) or to a control group [27]. Children who participated in LA Sprouts compared to controls experienced significant reductions in BMI z-scores and waist circumference, as well as improved vegetable and fiber intake [27]. To date, LA Sprouts is the only RCT gardening study that has shown promising effects of a garden and nutrition intervention on reducing obesity parameters in children [27]. However, this pilot study was not a cluster-RCT; it was conducted in an after-school setting, and was only 12 weeks long. Assessing gardening, nutrition, and cooking programs using a cluster-RCT in which the program is conducted during school hours for an entire school year is warranted.

Therefore, the overall goal of this project was to conduct a one-year, cluster RCT in elementary schools to examine the effect of a gardening, nutrition, and cooking program, called Texas Sprouts, on 3rd-5th grade children's dietary intake, obesity outcomes, and blood pressure. We hypothesized that the TX Sprouts intervention compared to the control group would result in the following changes in health outcomes; greater increases in FV intake and greater decreases in sugar sweetened beverage intake, obesity parameters and blood pressure in the intervention children.

\section{Methods \\ Study design and participants}

The complete design and methodology of this study has been previously published [28]. This is a school-based cluster RCT in which 16 elementary schools were block randomized by the study biostatistician who was blinded to either: (1) Texas Sprouts Intervention ( $n=8$ schools) or (2) Control (delayed intervention; $n=8$ schools). The intervention was implemented in three waves over three years, six schools (three intervention and three control) in wave 1 (2016-2017) and wave 2 (2017-2018) and four schools (two intervention and two control) in wave 3 (2018-2019). All schools had to meet the following inclusion criteria: (1) high proportion of Hispanic children (>50\%); (2) high proportion of children participating in the free and reduced lunch (FRL) program (>50\%), which represents a low-income population; (3) location 
within 60 miles of central Austin; and (4) no existing garden or gardening program.

All 3rd-5th grade students and parents at the recruited schools were contacted to participate via information tables at "Back to School" and "Meet the Teacher" events, flyers sent home with students, and teachers making class announcements in the fall after the garden had been built at the school. All recruitment materials were available in both English and Spanish. While all 3rd-5th grade students from participating schools received the lessons as part of their in-school curriculum, students/ parents had to provide informed written consent to participate in the evaluation measurements. Students and their parents signed assent and consent forms, respectively, approved by the Institutional Review Board (IRB) at UT Austin, as well as the research departments at each of the participating school districts.

\section{Sample size}

The sample size was estimated to test the effects of intervention on child vegetable intake (serving/day), BMI $\mathrm{z}$-scores, and waist circumference, with a power of $80 \%$ using a type I error of 0.05 , a two-sided test, and assuming equal allocation between the two arms $[29,30]$. Sample size estimation, variance $\left(\sigma^{2}\right)$ within schools, and the intra-cluster correlation coefficient (ICC) used change data from children who completed our pilot LA Sprouts study [27]. It was estimated that six schools each with 127 children for surveys and measurements were needed to detect the effect size of an increase in 0.5 in vegetable (serving/day) intake, a decrease of 0.065 in BMI z-scores, and a decrease of at least $0.02 \mathrm{~cm}$ in waist circumference. Two additional schools per arm were included in case a school decided to withdraw participation. For these reasons, a total sample size of 16 schools was used for this study.

\section{Intervention}

A social ecological-transactional model was used to shape the Texas Sprouts program, which treats the child as nested within immediate contexts or micro-systems (e.g., school, family, community) that reciprocally interact with each other and the child over time to shape development and behaviors [31, 32]. Texas Sprouts lessons were designed to improve a variety of diet-related psychosocial constructs, including increasing nutrition, gardening, and cooking knowledge, self-efficacy and attitudes, and a child's willingness to try and preference for $\mathrm{FV}$, and reducingP food insecurity, all of which would lead to increased FV intake and subsequent reductions in obesity parameters and blood pressure. While this analysis focuses on the effects of the intervention compared to control on the main outcomes of FV intake, obesity parameters and blood pressure, we will assess the intervention effects on these diet-related psychosocial variables and how changes in these variables mediate changes in the main outcomes in later analyses. Figure 1 denotes the logic model for this study.

Garden Leadership Committees (GLC) were formed at each intervention school and were comprised of interested stakeholders, such as teachers, parents, community members, school staff, and students. GLCs assisted with the following: a) physical garden design and build; b) hosting several garden workdays; and c) development and implementation of long-term garden maintenance and sustainability plan.

Gardens were built in every intervention school in the spring prior to the academic year of baseline measurements, with the help of the GLC. An average of $150 \mathrm{vol}$ unteers attended each garden build. All gardens included: raised vegetable beds; in-ground native and herb beds; a large shed for tools and materials; a whiteboard; and seating for classes. The schools were provided with the materials and supplies needed for garden upkeep (e.g. rakes, hoses, etc.) and for teaching the lessons, (e.g., tables, chairs/benches, cooking grill, portable hand-washing sink, pots/pans, etc.). FV and herbs planted in the garden were chosen based upon seasonality, soil type, and usage of recipes used in the curriculum, but included culturally-specific produce such as tomatoes, squash, peppers, and cilantro.

The Texas Sprouts curriculum was adapted from LA Sprouts [33] and Junior Master Gardener (JMG), a program developed by the Texas A\&M AgriLife Extension Service [34]. The following nutrition concepts were included in the final curriculum: (a) healthy cooking/preparation of FV (i.e., low in sugar and fat); (b) making nutritious food choices in different environments; (c) eating locally produced food; (d) low-sugar beverages made with fresh FV; (e) health benefits of FV; f) how to eat healthfully in food desert neighborhoods (neighborhoods lacking easy access to shops selling FV); and (g) food equity and community service. Full-time experienced and trained nutrition and garden educators, who all had college degrees in either horticultural, nutrition, or public health and at least three years of teaching nutrition and gardening lessons to children, taught 18 onehour Texas Sprouts lessons separately to each 3rd-5th grade class throughout the school year as part of their normal school day. Texas Sprouts curriculum included 18 lessons that were each $60 \mathrm{~min}$ in length, whereas the LA Sprouts curriculum only included 12 lessons that were each $90 \mathrm{~min}$ in length. However, the content covered in both curricula was essentially identical. Every lesson included either a garden taste-test (seven lessons) or a cooking activity (11 lessons) and a sampling of different "aguas frescas," which are flavored/infused waters with no added sugar. The student curriculum was 


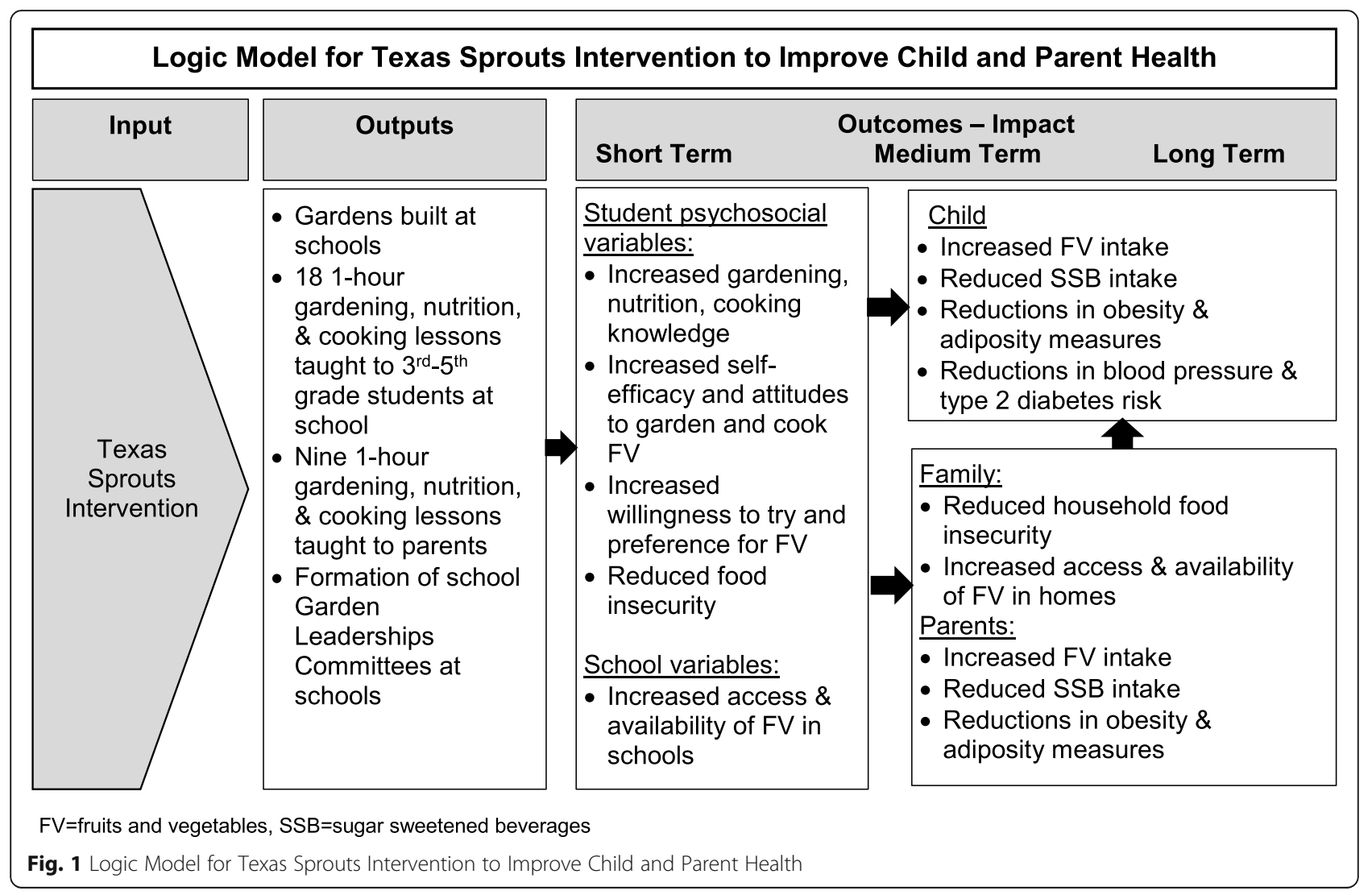

designed to be culturally tailored to Hispanics, including culturally appropriate recipes, content, and activities. This curriculum was designed with input from Hispanic families and tested in several pilot studies to ensure that the lessons were culturally sensitive and appropriate [27, 33, 35]. Every lesson was also mapped on Texas Essential Knowledge Standards (TEKS) for science, math, language arts, health, and social studies.

The parents' curriculum was adapted from the LA Sprouts program [33] and paralleled the nutrition and gardening topics/activities taught to the children. The parent curriculum also included the following topics; importance of family eating, healthy shopping, and increasing home available and access of healthy foods. The parent curriculum was available and taught in both English and Spanish. The garden/nutrition educators taught monthly 60-min Texas Sprouts lessons, for a total of nine lessons, throughout the school year. The dates and times varied widely across school sites, and parent classes were offered in mornings, during school hours, afterschool hours, evenings, and even on weekends to account for parent preferences and schedules at the various school sites. Parents were incentivized to attend the lessons with free meals, produce giveaways, groceries, water bottles, t-shirts, garden gloves, raffles for gift cards, and free childcare for children and siblings. The lessons were advertised and promoted by posting flyers, sending home newsletters, and sending out reminder text messages.

\section{Control}

The control schools received a delayed intervention (identical intervention as described above) in the year after the post-testing for that wave. Baseline and postintervention measurements occurred in the control parents and students within the same time period as the intervention schools. Every control school received a garden, identical in size and structure to the intervention schools. Trained educators taught the 18 school lessons and monthly family lessons at the schools.

\section{Outcome measurements}

Data were collected on children and parents at baseline (within the first month of the beginning of the academic school year) and post-intervention (within the last month of the academic school year). Approximately 10 trained research staff went to each school for a full week to collect all measures at each school. Of note, the Texas Sprouts educator did not participate in the data collection at their respective schools.

Height was measured using a free-standing stadiometer mounted against the wall, to the nearest $0.1 \mathrm{~cm}$ 
(Seca, Birmingham, UK). Waist circumference was measured using NHANES protocol [36]. Weight and bioelectrical impedance were assessed with the Tanita Body Fat Analyzer (model TBF 300$)$. BMI $\left(\mathrm{kg} / \mathrm{m}^{2}\right)$ and BMI percentiles were determined using CDC age- and gender-specific values [37]. Blood pressure was measured with an automated monitor with child or adult cuffs (Omron, Schaumberg, IL). Children were asked questions about their age, grade, and sex on a survey. An adapted version of the 2015 School Physical Activity and Nutrition (SPAN) dietary screener was used to assess $\mathrm{FV}$ and sugar sweetened beverage consumption in the children [38]. This screener included 14 items, 8items for vegetables, 2-items for fruit, and 4-items for beverages and each item asked about consumption frequency per day. The items on the screener matched up with what grows in the garden. We assessed the validity of the expanded SPAN questionnaire with a two independent samples $(n=70)$ of children (9-11 y) [39], where vegetable intake reported via questionnaire was compared to that reported via 24-h dietary recalls. Agreement correlations for vegetable items ranged from 0.35 to 0.71 with percentage agreements ranging from 57 to $87 \%$, which suggested moderate to strong agreement [40]. We assessed reliability of this adapted SPAN screener with a separate independent sample $(n=76)$ of children (9-11 y). Test-retest percent agreement was between 71 and $84 \%$ for all seven items, which is considered to be moderately reproducible [41]. The final questionnaire packet also included questions on food and meal choice behaviors [42], self-efficacy to cook and/or prepare FV and gardening [33, 43], willingness to try and preferences for FV [44, 45], cooking and gardening attitudes [33], nutrition and gardening knowledge [33], and child food security [46].

Parents were asked to complete a questionnaire packet, which was either given to them at back-to-school or meet-the-teacher nights or brought home to them in their child's backpack. For this paper, the only parent data that were used was the baseline information regarding their child's race/ethnicity, and participation in the free and reduced lunch program. However, the parent questionnaire packet included questions on family eating activities [45], household food insecurity, parental dietary intake [47], and home availability of FV [45].

\section{Dose, reach, and Fidelity of intervention}

Texas Sprouts educators completed brief process logs after each child and parent lesson that included: attendance, classes taught outside, number of deviations from planned class activities, number of behavioral disturbances, classroom teacher involvement and student perception/feedback of the lesson's recipe and taste test of aguas frescas. For "dose", the number of activities performed within each class was divided by the number of activities scheduled. For "reach", the number of all children in class and parents with consent attending all the classes was divided by the number of participating children and parents. In addition, an observation survey was developed to assess the educators' implementation of the lesson. Key study personnel observed each Texas Sprouts educator at least twice per year and completed this observation survey. Both the process logs and observation surveys permitted constructive feedback, additional coaching from key study personnel and iterative learning if performance fell below expected level. Research staff also recorded GLC member information, leadership structure, meeting times/places, sustainability workshops offered/attended, fundraising and media garden events, types of produce grown and harvested, produce use and distribution plans, and community resources leveraged.

\section{Data management}

Study data were collected and managed using REDCap (Research Electronic Data Capture) [48]. Statistical Analyses were completed in SAS version 9.4-TSlevel1M6. Following the recommendations by the National Research Council (US) Panel on Handling Missing Data in Clinical Trials [49]. We are reporting the results of the trial using three type of analysis under three different assumptions to handle missing values for the variables of interest: Complete case analysis (CCA), available case analysis (ACA) and multiple imputation under the missing at random assumption (MI). Children who provided complete data for primary outcomes (i.e., height, weight, BMI, BMI Z-Score, BMI percentile, waist circumference, percentage body fat, systolic and diastolic blood pressure, FV intake, and sugar sweetened beverages from the screener) were used for the complete case analysis, and therefore a fixed sample size was used under this assumption. These same variables are reported for the available case analyses but the sample size changed depending on the number of observations missing in the pre-intervention or post-intervention analyses. We assumed that the missing values of the variables of interest were missing at random and the multiple imputation technique using 10 imputations under a multivariate normal model. The variables included in the imputation model were: sex, age, pre and post primary outcomes, percentage of free and reduce lunch pre and post intervention, and the interaction of the child race/ethnicity. A thousand iterations were used for the burning process and then every ten thousand iterations were used to draw one of the 10 imputations from the model. Autocorrelations and time plots were checked for convergence of the imputation process. A type I error level of 0.05 was used to determine statistical significance of all 
two-sided statistical tests, and final analyses are presented using Rubin's rules for reporting weighted summary statistics and $p$-values from the 10 multiple imputations [50]. Weighted cluster summary statistics, and frequency distributions were used to describe preintervention characteristics and the change between the pre-intervention and the post intervention characteristics between the eight intervention schools and the eight control schools. Selection of children was assumed to be random within the school.

\section{Data analyses}

Generalized weighted linear mixed models (GLMM) $[29,30]$ with the identity link were used to test differences between the intervention and the control estimates, with the weighted mean and weighted standard deviations with schools as random clusters for continuous variables (Tables 2 and 3), as well as for the mean of the percentage change in categorical variables (Table 4). GLMM under a multinomial distribution under the cumulative logit link was used for multinomial variables to test for the differences between the intervention and the control schools again assuming the schools as random clusters (Table 3). We implemented Sidak's methods [51] to account for multiple comparisons pairwise t-tests on the differences in the mean percentages between the intervention and control groups (Table 4).

\section{Results}

Figure 2 shows enrollment, randomization and participation in the Texas Sprouts study. Of the 4239 eligible children at the 16 schools, 3302 children (or 78\%) consented to be in the study. Of those consented, 3135 children ( $74 \%$

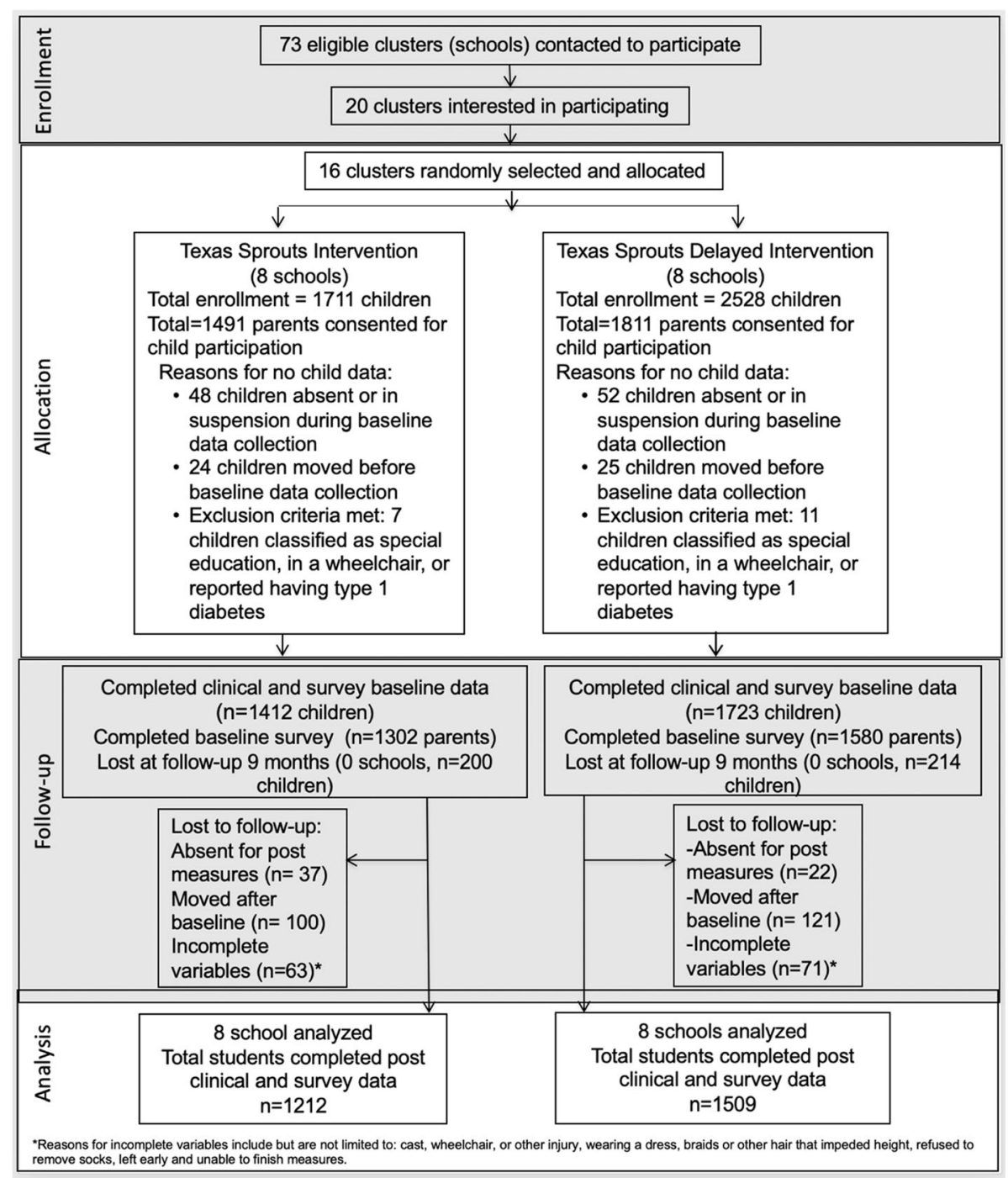

Fig. 2 Texas Sprouts Consort Diagram 
of eligible children or $95 \%$ of those consented) completed baseline clinical measures and child surveys and were in the clinical trial. The intervention group included 1412 children (or 45\%) and the control group included 1723 children. Approximately 92\% (or $n=2876, n=1302$ parents in intervention and $n=1580$ parents in control) parents completed baseline surveys. Of the 3135 children who completed baseline clinical and survey measures, 2721 (or 87\%) completed post-intervention clinical and survey measures $(n=1212$ in intervention group and $n=$ 1509 in control group).

Complete case and multiple imputation analyses of child baseline demographics of the intervention and control schools are shown in Table 1. The average age of children was 9.2 years and $47 \%$ were male. Approximately $64 \%$ were Hispanic, and the average percent of children receiving free and reduced breakfast/lunch was $69 \%$. There were no significant differences in any of the demographic variables between intervention and control schools.

Dose and reach of student and parent classes are reported in Table 2. Texas Sprouts lessons were taught by hired educators during school hours, and make-up days were planned if a lesson was not taught, therefore $100 \%$ of the classes were taught to each classroom in grades 3-5. Sometimes classes were shortened (due to testing, assemblies, fire alarms, etc.), but less than $1 \%$ of the 18 lessons were modified or shortened across all eight intervention schools. In addition, child lessons were designed to be taught outside, but due to weather issues (i.e., rain, wind, too hot or too cold temperatures), 34\% of classes were taught indoors in a classroom. Parent classes were much less attended, despite multiple attempts to offer make-up classes. Only $88.9 \%$ of the parent classes were taught, due to no parents showing up for some classes. Only $7.1 \%$ of participating parents $(n=$ 106) attended one or more Texas Sprouts parent lesson. The average number of parent classes attended was $2.0 \pm 1.6$, with a range of $1-9$. Less than $1 \%$ (or $n=11$ ) parents attended $50 \%$ or more of the offered parent classes (or attended 5 of the 9 classes).

Complete case and multiple imputations analyses of intervention effects on clinical and dietary intake data are shown in Table 3. Using multiple imputation analyses, the intervention compared to control resulted in increased vegetable intake $(+0.33$ vs. +0.03 freq $/ \mathrm{d}, p<$ 0.01). Similarly, using complete case analyses, the intervention compared to control resulted in increased vegetable intake $(+0.48$ vs. $+0.04 \mathrm{freq} / \mathrm{d}, p=0.02)$. The intervention compared to control did not affect fruit or sugar sweetened beverage (SSB) intake. The intervention did not have an effect on any BMI parameters, body fat percentage, waist circumference, or blood pressure. We also analyzed the data using available case analyses, and
Table 1 Differences in child demographic, clinical, and dietary characteristics between Texas Sprouts intervention and control groups at baseline

\begin{tabular}{|c|c|c|c|c|}
\hline & $\begin{array}{l}\text { Total } \\
\text { Mean (SE) }\end{array}$ & $\begin{array}{l}\text { Intervention } \\
\text { Mean }(\mathrm{SE})^{\mathrm{a}}\end{array}$ & $\begin{array}{l}\text { Control } \\
\text { Mean }(S E)^{a}\end{array}$ & P-value** \\
\hline \multicolumn{5}{|c|}{ Sample size } \\
\hline CCA & 2721 & 1212 & 1509 & NA \\
\hline $\mathrm{Ml}$ & 3135 & 1412 & 1723 & NA \\
\hline \multicolumn{5}{|l|}{ Age (y) } \\
\hline CCA & $9.24(0.07)$ & $9.28(0.07)$ & $9.20(0.07)$ & 0.33 \\
\hline $\mathrm{Ml}$ & $9.23(0.02)$ & $9.26(0.06)$ & $9.20(0.06)$ & 0.47 \\
\hline \multicolumn{5}{|c|}{ Male (\%) (SE) } \\
\hline CCA & $47.16(3.88)$ & $46.42(4.08)$ & $47.89(3.67)$ & 0.45 \\
\hline $\mathrm{Ml}$ & $47.35(3.61)$ & $46.99(3.79)$ & $47.71(3.44)$ & 0.59 \\
\hline \multicolumn{5}{|c|}{ Race/ethnicity \% (SE) } \\
\hline \multicolumn{5}{|l|}{ White } \\
\hline CCA & $19.82(2.75)$ & $21.28(2.76)$ & $18.37(2.73)$ & 0.86 \\
\hline $\mathrm{Ml}$ & $19.69(2.58)$ & $20.90(2.67)$ & $18.48(2.51)$ & 0.87 \\
\hline \multicolumn{5}{|l|}{ Black } \\
\hline CCA & $8.91(2.22)$ & $8.61(2.23)$ & $9.21(2.20)$ & 0.91 \\
\hline $\mathrm{MI}$ & $11.10(2.23)$ & $11.19(2.32)$ & $11.02(2.16)$ & 0.85 \\
\hline \multicolumn{5}{|c|}{ Hispanic } \\
\hline CCA & $65.80(3.46)$ & $64.75(3.46)$ & $66.86(3.45)$ & 0.92 \\
\hline MI & $63.67(3.25)$ & $62.23(3.29)$ & $64.42(3.21)$ & 0.89 \\
\hline \multicolumn{5}{|c|}{ Nat.Amer/Asian/Pac.Island/Other } \\
\hline CCA & $5.47(1.72)$ & $5.37(1.79)$ & $5.57(1.65)$ & 0.89 \\
\hline MI & $5.88(1.64)$ & $5.68(1.69)$ & $6.08(1.61)$ & 0.75 \\
\hline \multicolumn{5}{|c|}{ Eligible FRL \%(SE) } \\
\hline CCA & $68.91(3.55)$ & $66.62(3.69)$ & $71.21(3.41)$ & 0.68 \\
\hline $\mathrm{MI}$ & $68.25(3.21)$ & $66.47(3.38)$ & $69.43(3.07)$ & 0.78 \\
\hline
\end{tabular}

CCA complete case analyses; $M I$ multiple imputation; FRL free and reduced school lunch; Nat. Amer Native American; Pac Island Pacific Islander $\mathrm{MI}$ analyses is required for all clinical trials and CCA is what is more commonly reported, therefore, both $\mathrm{MI}$ and CCA are reported here

${ }^{a}$ Weighted mean and standard error (SE) of each variable. Weighted refers to the total number of children within each school

**Generalized linear mixed models (GLMM) with linear link was used to compute $p$-values of the continuous variables, GLLM with cumulative logit link was used to compute $p$-values of the categorical variables

those results are in the Appendix Table. The results were very similar for the available case analyses. Table 4 shows the changes in BMI status between intervention and control schools. After adjustments were made for multiple comparisons, there was no significant effect of the intervention on BMI status.

\section{Discussion}

Contrary to our hypotheses, the Texas Sprouts intervention, compared to the control group, did not reduce obesity parameters or blood pressure, but resulted in significant increases in vegetable intake. While 
Table 2 Dose and reach of Texas Sprouts intervention components

\begin{tabular}{|c|c|c|c|}
\hline $\begin{array}{l}\text { Intervention } \\
\text { component }\end{array}$ & $\begin{array}{l}\text { Process } \\
\text { Evaluation }\end{array}$ & Output & Overall (\%) \\
\hline \multirow[t]{2}{*}{$\begin{array}{l}\text { Texas Sprouts } \\
\text { student Lesson }\end{array}$} & Dose delivered & $\begin{array}{l}\% \text { of classes delivered } \\
\% \text { of activities taught } \\
\text { during class } \\
\% \text { taught outside }\end{array}$ & $\begin{array}{l}100 \% \\
98.5 \% \\
66 \%\end{array}$ \\
\hline & Reach & $\begin{array}{l}\% \text { of students attending } \\
\text { each class }\end{array}$ & $96 \%$ \\
\hline \multirow[t]{2}{*}{$\begin{array}{l}\text { Texas Sprouts } \\
\text { Parent Lesson }\end{array}$} & Dose delivered & $\begin{array}{l}\% \text { of classes delivered } \\
\% \text { of activities taught } \\
\text { during class }\end{array}$ & $\begin{array}{l}88.9 \% \\
100 \%\end{array}$ \\
\hline & Reach & $\begin{array}{l}\% \text { of consented parents } \\
\text { who attended at least } \\
\text { one class } \\
\% \text { of consented parents } \\
\text { who attended } \geq 50 \% \text { of } \\
\text { classes ( } 5 \text { or more of the } \\
9 \text { offered classes) }\end{array}$ & $\begin{array}{l}7 \% \\
<1 \%\end{array}$ \\
\hline
\end{tabular}

interventions that increase FV intake have been shown to reduce obesity parameters in adults [6], the results from experimental studies with children have yielded mixed results $[52,53]$. Several RCTs with youth have found that nutrition interventions that result in increased vegetable intake have also resulted in reductions in BMI [54] and abdominal adiposity [52], while other studies have shown no effect on obesity levels [53]. Our 12-week afterschool LA Sprouts garden pilot study resulted in improvements in vegetable and fiber intake and reductions in BMI zscores and waist circumferences [27]. A likely reason that our shorter LA Sprouts program resulted in reductions in obesity parameters, whereas Texas Sprouts did not, is that only two schools received the LA Sprouts program compared to two control schools and the analyses were done on the individual level controlling for school, therefore it was not a cluster analyses. Another possible explanation is that the intensity of the programs varied, in that 12 LA Sprouts lessons, each 90 min in length, were taught weekly for 12 weeks, compared to 18 Texas Sprouts lessons, 60 min in length, that were taught more sporadically throughout the school year. It is also possible that the effects of increasing vegetable intake on reducing obesity parameters requires more intense dissemination initially and/or longer follow-up.

In general, over the past three decades, school-based interventions targeting obesity reductions have yielded mixed results [55-57]. A meta-analysis of 19 schoolbased RCTs, found that school-based nutrition and/or physical activity interventions were not effective at decreasing BMI compared to control groups [57]. In contrast, another meta-analyses with eight studies showed that school-based nutrition and physical activity intervention did result in reductions in body weight compared to control groups [58]. Research does consistently show that school programs when implemented with complementary community and parent programs can significantly prevent and treat childhood obesity $[59,60]$. The available evidence does suggest that no single intervention, in school or elsewhere, is likely to be sufficient to reverse childhood obesity, and that a combined multicomponent approach targeting children, parents, the school and the community environment are needed to treat and prevent childhood obesity $[61,62]$. In addition, it is important to examine the effects of such multicomponent interventions on health benefits beyond obesity parameters, such as metabolic outcomes.

It is also possible that the positive weight loss effects of FV intake are more linked to the displacement of other energy dense foods. In a family-based intervention conducted by Epstein et al. families assigned to a 6month intervention focused on increasing FV resulted in both increased FV intake and reductions in high fat/ sugar foods, and decreased percentage of overweight within the parents, but not child overweight percentages. Whereas families assigned to a 6-month intervention focused solely on decreasing high fat/sugar foods resulted in reductions in high fat/sugar foods, but no effect on changes in FV intake or parental and child overweight percentages [53]. Other interventions have targeted both the increase in FV along with the decrease in high fat and sugary foods and beverages [52, 63]. While the main focus of the Texas Sprouts lessons was to increase FV, we also focused on reducing added sugar, specifically sugar sweetened beverages (SSBs). All 18 Texas Sprouts lessons included a lesson focused entirely on reducing SSBs and every lesson included a tasting of a different agua fresca, or infused water with no added sugar. Contrary to our hypothesis, the intervention did not result in reductions in SSBs. However, the measurement of SSB intake may have been limited given there was only one item measuring this behavior on our survey. Regardless, the increase in vegetable intake, without subsequent displacement of energy dense beverages and/or snacks might explain the null effects of the intervention on obesity measures.

Parent modeling and intake of FV has been consistently shown in the literature to be linked to increased FV intake in the child $[64,65]$. While the current study included monthly parent lessons, and was designed to reach both the children at schools and the families at home, parent participation was extremely poor. Only $7 \%$ of the participating parents came to one or more parent class. Of those parents that did attend, less than $1 \%$ attended $50 \%$ of the offered monthly lessons (or 5 of the 9). Despite the incentives (i.e., free babysitting, meals, produce giveaways), reminders, and accommodations (i.e., scheduling classes before, during, and after school and on weekends) that were made to increase parental 
Table 3 Effects of the Texas Sprouts intervention compared to Control on clinical and dietary outcomes

\begin{tabular}{|c|c|c|c|c|c|}
\hline \multirow[t]{3}{*}{ Outcomes* } & \multicolumn{2}{|c|}{$\begin{array}{l}\text { Intervention ( } n=8 \text { schools) } \\
\text { CCA } n=1212 \\
\text { MI } n=1412\end{array}$} & \multicolumn{2}{|c|}{$\begin{array}{l}\text { Control ( } n=8 \text { schools) } \\
\text { CCA } n=1509 \\
\text { MI } n=1723\end{array}$} & \multirow[t]{3}{*}{$\begin{array}{l}\text { Intervention Effect } \\
\text { P-value }\end{array}$} \\
\hline & Pre & Change & Pre & Change & \\
\hline & Mean (SE)* & Mean (SE)* & Mean $(\mathrm{SE})^{*}$ & Mean $(\mathrm{SE})^{*}$ & \\
\hline \multicolumn{6}{|l|}{ Height (cm) } \\
\hline CCA & 138.24(0.69) & $4.12(0.11)$ & $137.52(0.63)$ & $3.71(0.11)$ & 0.07 \\
\hline $\mathrm{Ml}$ & $138.22(0.64)$ & $4.12(0.11)$ & $137.46(0.59)$ & $3.71(0.10)$ & 0.06 \\
\hline \multicolumn{6}{|l|}{ Weight (kg) } \\
\hline CCA & $38.89(0.99)$ & $3.02(0.22)$ & $38.57(0.89)$ & $2.82(0.17)$ & 0.32 \\
\hline $\mathrm{Ml}$ & $38.87(0.91)$ & $3.03(0.21)$ & $38.61(0.84)$ & $2.83(0.16)$ & 0.28 \\
\hline \multicolumn{6}{|l|}{ BMI $\left(\mathrm{kg} / \mathrm{m}^{2}\right)$} \\
\hline CCA & $20.03(0.05)$ & $-0.33(0.09)$ & 20.05(0.33) & $-0.35(0.08)$ & 0.84 \\
\hline $\mathrm{Ml}$ & $20.03(0.35)$ & $0.33(0.09)$ & $20.08(0.31)$ & $0.35(0.07)$ & 0.87 \\
\hline \multicolumn{6}{|l|}{ BMI z-score } \\
\hline CCA & $0.78(0.09)$ & $0.05(0.03)$ & $0.81(0.08)$ & $0.03(0.02)$ & 0.36 \\
\hline $\mathrm{Ml}$ & $0.77(0.09)$ & $-0.04(0.03)$ & $0.81(0.08)$ & $-0.02(0.02)$ & 0.51 \\
\hline \multicolumn{6}{|c|}{ BMI Percentile } \\
\hline CCA & $70.11(2.34)$ & $1.20(0.70)$ & 70.98(2.13) & $0.60(0.65)$ & 0.39 \\
\hline $\mathrm{Ml}$ & $69.99(2.18)$ & $-0.82(0.70)$ & 71.05(1.99) & $-0.39(0.64)$ & 0.53 \\
\hline \multicolumn{6}{|c|}{ Waist Circumference (cm) } \\
\hline CCA & $71.34(1.02)$ & $1.10(0.31)$ & $70.62(0.90)$ & $1.50(0.27)$ & 0.31 \\
\hline $\mathrm{Ml}$ & $71.29(0.95)$ & $1.16(0.29)$ & $70.67(0.86)$ & $1.53(0.25)$ & 0.34 \\
\hline \multicolumn{6}{|c|}{ Percentage Body Fat } \\
\hline CCA & $25.91(0.73)$ & $-0.33(0.22)$ & 26.09(0.64) & $-0.51(0.19)$ & 0.47 \\
\hline $\mathrm{Ml}$ & $25.87(0.68)$ & $-0.34(0.21)$ & $26.10(0.60)$ & $-0.49(0.18)$ & 0.40 \\
\hline \multicolumn{6}{|c|}{ Systolic BP (Hg/mm) } \\
\hline CCA & $104.07(0.97)$ & $-0.31(0.93)$ & $102.74(0.86)$ & $0.02(0.89)$ & 0.81 \\
\hline $\mathrm{Ml}$ & $104.10(0.91)$ & $-0.39(0.90)$ & $102.54(0.80)$ & $0.20(0.85)$ & 0.64 \\
\hline \multicolumn{6}{|c|}{ Diastolic BP (Hg/mm) } \\
\hline CCA & $68.53(0.81)$ & $-1.20(0.88)$ & $66.21(0.70)$ & $0.22(0.80)$ & 0.28 \\
\hline $\mathrm{Ml}$ & $68.64(0.77)$ & $-1.33(0.84)$ & $66.10(0.65)$ & $0.32(0.76)$ & 0.18 \\
\hline \multicolumn{6}{|c|}{ Vegetable intake (freq/d) } \\
\hline CCA & $2.74(0.23)$ & $0.46(0.25)$ & $2.94(0.22)$ & $0.03(0.23)$ & 0.02 \\
\hline Ml & $2.01(0.12)$ & $0.33(0.13)$ & $2.11(0.11)$ & $0.03(0.11)$ & 0.002 \\
\hline \multicolumn{6}{|c|}{ Fruit intake (freq/d) } \\
\hline CCA & $1.27(0.08)$ & $0.15(0.11)$ & $1.22(0.08)$ & $0.13(0.09)$ & 0.77 \\
\hline $\mathrm{Ml}$ & $1.28(0.08)$ & $0.15(0.10)$ & $1.23(0.07)$ & $0.13(0.09)$ & 0.80 \\
\hline \multicolumn{6}{|l|}{ SSB (freq/d) } \\
\hline CCA & $0.58(0.06)$ & $0.01(0.08)$ & $0.61(0.06)$ & $0.09(0.08)$ & 0.15 \\
\hline $\mathrm{Ml}$ & $0.57(0.06)$ & $0.05(0.08)$ & $0.62(0.06)$ & $0.11(0.07)$ & 0.24 \\
\hline
\end{tabular}

$C C A$ complete case analyses; $M I$ multiple imputation; BMI body mass index; BP blood pressure; Freq/d frequency per day; SSB sugar sweetened beverages *Weighted mean and standard error (SE) of each variable. Weighted refers to the total number of children within each school. Generalized weighted linear mixed models (GLMM) assessed differences between intervention and control groups

attendance, participation was poor in every intervention school. The top reasons parents gave for not attending the lessons was lack of transportation and not having enough time. Other school-based interventions have shown success with delivering parental nutrition education through telephone counseling [66], text messaging 
Table 4 Change in BMl status between intervention and control

\begin{tabular}{lllllll}
\hline Pre-Intervention & Post-Intervention & $\begin{array}{l}\text { Intervention }(\mathbf{m}=\mathbf{8}) \\
\text { Mean percentage of } \\
\text { students by school (SE) }\end{array}$ & $\begin{array}{l}\text { Control }(\mathbf{m}=\mathbf{8}) \\
\begin{array}{l}\text { Mean percentage of } \\
\text { students by school (SE) }\end{array}\end{array}$ & $\begin{array}{l}\text { Differences in } \\
\text { Mean } \\
\text { percentage (SE) }\end{array}$ & $\begin{array}{l}\text { Intervention } \\
\text { Effect } \\
\mathbf{p} \text {-valuet }\end{array}$ & $\begin{array}{l}\text { Sidak } \\
\mathbf{p}- \\
\text { value+ }\end{array}$ \\
\hline Normal/underweight & Normal/underweight & $52.64(2.09)$ & $49.34(1.81)$ & $-3.3(2.76)$ & 0.25 \\
Normal/underweight & Overweight & $2.68(0.42)$ & $2.83(0.45)$ & $0.15(0.614)$ & 0.81 & 0.93 \\
Normal/underweight & Obese & $0.26(0.17)$ & $0.33(0.14)$ & $0.07(0.222)$ & 0.75 & 1 \\
Overweight & Normal/underweight & $3.69(0.55)$ & $5.42(0.45)$ & $1.74(0.712)$ & 0.03 & 0.23 \\
Overweight & Overweight & $11.75(1.15)$ & $13.04(0.95)$ & $1.3(1.49)$ & 0.40 & 0.99 \\
Overweight & Obese & $1.42(0.37)$ & $1.88(0.41)$ & $0.46(0.55)$ & 0.42 & 0.99 \\
Obese & Normal/underweight & $0.21(0.11)$ & $0.06(0.06)$ & $-0.15(0.12)$ & 0.22 & 0.90 \\
Obese & Overweight & $3.08(0.51)$ & $2.60(0.39)$ & $-0.49(0.64)$ & 0.46 & 1 \\
Obese & Obese & $24.28(1.64)$ & $24.50(1.40)$ & $0.22(2.15)$ & 0.92 & 1 \\
\hline
\end{tabular}

$B M I$ body mass index

${ }^{a}$ Weighted mean percentage and standard error of the mean percentage (SE) of each category change. Weighted refers to total number of participants within each school

${ }^{b}$ Differences of the weighted mean percentage between intervention and control and standard error of the differences in the weighted mean percentage of each category change

TT-Tests were used to determine differences in categorical weight status between intervention and control groups by each change of weight status combination +Sidak p-value: adjusted for multiple comparison

[67], websites [68], family-fun nights [69], or newsletters/home assignments [43]. However, parental reach in these types of studies is unclear. While there is evidence that parent participation can reduce obesity among children who are overweight or obese in home or clinical settings [70,71], the evidence is unclear on how parental participation in school based interventions plays a role in obesity prevention in children.

Despite the lack of parental support in the current study, our study did result in in significant and meaningful increases in vegetable intake. In 2017, a review of gardening interventions found that ten of the 14 studies included showed significant improvements in FV intake [23]. Despite the long-term benefits of FV, less than half of the children in the US are consuming the recommended FV intake [9]. Thus, school garden-based interventions offer a promising intervention to effectively increase FV intake in children, which may have a myriad of long-term health benefits beyond the effects on obesity, including reductions in asthma, inflammation, cardiovascular disease, cancer risk, type 2 diabetes risk factors, and improvements in immune response [72-74].

The Whole School, Whole Communities, Whole Child model suggest that health and education must work together whenever possible [75]. Currently, 40 states require nutrition education for all students, yet only 15 states' explicitly address teacher professional development for health education [76]. This means that most U.S. teachers are mandated to teach nutrition education with little or no training and few curricular resources. Given that schools are one of the most efficient systems for reaching $95 \%$ of all U.S. youth and the mandates for schools to teach nutrition education exist, infusing garden and nutrition education into schools offers a practical, meaningful and sustainable way to improve the health of our children.

In addition, the majority of the children in this study receive free and/or reduced breakfast and lunch meals through the National School Lunch Program (NSLP) and the School Breakfast Program (SBP), which means that approximately two thirds of their overall energy intake likely comes from the school. While over the past decade, important policy revisions have been made to the NSLP and SBP, which have resulted in increases FV consumption [77, 78] and increases in healthy eating index scores [79] in school meals, there is still much work to be done to continue to increase the quality of school meals. While the current study exposed children at schools to additional FV during the student lessons, the foodservice department was not involved in the intervention nor was the produce yield from the school garden enough to supplement the school meals in any way. If garden-based interventions incorporated the foodservice more into their programming or grew more produce to supplement the food in the cafeteria, there might even be more improvements in dietary intake among the children.

All Texas Sprouts lessons were taught by well-trained and paid nutrition and gardening educators, in order to control for dosage and reach, and to fully test the effects of the program as designed. However, this does limit the ability to sustain the program moving forward. In the year after the intervention, all 16 schools received a series of garden-based training workshops led by the 
Sustainable Food Center (SFC), a local non-profit organization that offers school garden trainings, and consultant on this grant. All teachers at that school, not just those that received the Texas Sprouts lessons, were invited to participate in these 2-h workshops, that were either held at the school or at SFC. These workshops covered basic information on gardening, maintenance of physical garden, garden leadership structure and organization, information about local resources/materials, and covered available funding sources. In addition, we secured additional funding from the Sprouts Healthy Communities Foundation to continue to work with these 16 schools to support additional teacher training, at the individual, grade level and whole school level, as well as access to curriculum and resources to continue Texas Sprouts programming. We have recently surveyed 573 school teachers and 173 school administrators on barriers and strategies for sustaining successful school gardening programs, and adequate teacher training, existence of garden leadership committee, and available curriculum were among the top predictors of having a thriving school garden program (paper in review).

There are several other limitations to discuss. The sample was predominately low-income and Hispanic; therefore, results are not generalizable to other race/ ethnicities and income levels. However, that was by design, as low-income Hispanic children are at increased risk for obesity. The dietary data was selfreported and the validity and reliability of the adapted SPAN questionnaire only yielded moderate to strong agreement with the 24-h diet recalls and moderate reproducibility. Another limitation is that the intervention is only one school year long, and that follow-up testing may be needed to see long-term effects of increasing vegetable intake on obesity outcomes. In addition, it would have been ideal to add follow-up measures on the control group after receiving the delayed intervention, but this was logistically and financially not possible on a 5-year NIH grant. However, we intend to write additional grants to collect followup measures on this cohort. While the current intervention included monthly parent lessons, they were very poorly attended and school-based interventions effectively reaching both the child and parent are warranted. Another limitation is that approximately one third of the garden classes had to be held indoors because of weather, however the full cooking, gardening, and nutrition lesson was still taught indoors. Another limitation is that the current analyses only included the effects of the intervention on the main outcomes (obesity outcomes, blood pressure, and FV and SSB intake), as these variables had the most complete pre/post data and missing at random and multiple imputation (MI) techniques were used for each of these outcomes. In addition, the study was powered on these main outcomes. We did collect other secondary data pre- and post-intervention including: dietary psychosocial variables via survey, academic performance, physical activity via survey and accelerometers, and 24-h dietary recalls, skin carotenoids and fasting blood draws in a subsample of the children. However, as mentioned above, that data is much less complete and/or only collected in a subsample, and the analyses plan would be different for those variables. We intend to examine the effects of the intervention using complete case data on all of those other variables in future analyses.

\section{Conclusions}

This was the first school-based cluster RCT to examine the effects of a school gardening, nutrition, and cooking program on obesity measures and blood pressure. While the intervention did not reduce obesity parameters or blood pressure, it did result in significant and meaningful increases in vegetable intake. The effects of increase vegetable intake on obesity markers might just take longer to reduce obesity markers in pediatric populations. In addition, it important to examine how increased vegetable intake may result in other improvements in health parameters, beyond obesity parameters. We intend to assess the effects of the Texas Sprouts intervention on a variety of metabolic measures obtained from the fasting blood draw, such as glucose, HbA1c, lipids, metabolic syndrome and inflammatory markers. In addition, we intend to assess the effects of the Texas Sprouts intervention on diet-related psychosocial data, energy, macronutrients, healthy eating index, and skin carotenoids, in the near future. We can also examine what behavior changes mediated the increases in vegetable intake and other potential health improvements. School-based garden programs are effective at reaching large numbers of children, fit well into existing school standards and curriculum, provide opportunities for schools to meet nutrition education mandates, and have consistently resulted in increasing vegetable intake in children. There is a need for longer-term follow-up of school-based garden programs. There is also a need to better engage parents in school-based garden programs. Sustaining school garden programs is also challenging. School gardens should be assimilated more into the school culture and curriculum, used by more teachers and students, integrated more into the foodservice and cafeteria, and supported and used more by parents and the community. Research is warranted to help schools succeed at sustaining their school gardening programs. 


\section{Appendix}

Table $\mathbf{5}$ Intervention effects on clinical and dietary outcomes using available case analyses

\begin{tabular}{|c|c|c|c|c|c|c|c|c|}
\hline \multirow[t]{3}{*}{ Outcomes $^{a}$} & \multirow[b]{3}{*}{ Total $n$} & \multicolumn{3}{|c|}{$\begin{array}{l}\text { Intervention } \\
(\mathrm{m}=8 \text { schools })\end{array}$} & \multicolumn{3}{|c|}{$\begin{array}{l}\text { Control } \\
\text { ( } m=8 \text { schools) }\end{array}$} & \multirow{3}{*}{$\begin{array}{l}\text { Intervention } \\
\text { Effect } \\
\text { P-value }\end{array}$} \\
\hline & & & Pre & Change & & Pre & Change & \\
\hline & & $\mathrm{n}$ & Mean (SE) & Mean (SE) & $\mathbf{n}$ & Mean (SE) & Mean (SE) & \\
\hline Height (cm) & 2849 & 1274 & $138.20(0.64)$ & $4.11(0.11)$ & 1575 & $137.46(0.59)$ & $3.71(0.11)$ & 0.07 \\
\hline Weight (kg) & 2845 & 1272 & $38.85(0.91)$ & $3.03(0.22)$ & 1573 & $38.61(0.84)$ & $2.84(0.17)$ & 0.32 \\
\hline BMI $\left(\mathrm{kg} / \mathrm{m}^{2}\right)$ & 2844 & 1272 & $20.03(0.35)$ & $-0.33(0.09)$ & 1572 & $20.08(0.31)$ & $-0.36(0.07)$ & 0.84 \\
\hline BMI z-score & 2844 & 1272 & $0.77(0.09)$ & $0.05(0.03)$ & 1572 & $0.81(0.08)$ & $0.03(0.02)$ & 0.42 \\
\hline BMI Percentile & 2844 & 1272 & $70.01(2.18)$ & $1.13(0.68)$ & 1572 & 71.04(1.99) & $0.58(0.63)$ & 0.42 \\
\hline Waist Circumference $(\mathrm{cm})$ & 2840 & 1271 & $71.28(0.95)$ & $1.13(0.31)$ & 1569 & $70.65(0.86)$ & $1.54(0.26)$ & 0.30 \\
\hline Body Fat (\%) & 2843 & 1271 & $25.86(0.68)$ & $-0.35(0.22)$ & 1572 & $26.09(0.61)$ & $-0.49(0.19)$ & 0.47 \\
\hline Systolic BP (Hg/mm) & 2840 & 1274 & 104.12(0.91) & $-0.30(0.91)$ & 1566 & $102.54(0.81)$ & $0.13(0.88)$ & 0.76 \\
\hline Diastolic BP (Hg/mm) & 2840 & 1274 & $68.66(0.78)$ & $-1.25(0.87)$ & 1566 & $66.10(0.65)$ & $0.26(0.79)$ & 0.25 \\
\hline Vegetable intake (freq/d) & 2800 & 1249 & $2.76(0.22)$ & $0.47(0.25)$ & 1551 & $2.95(0.21)$ & $0.01(0.23)$ & 0.01 \\
\hline Fruit intake (freq/d) & 2828 & 1261 & $1.28(0.08)$ & $0.15(0.10)$ & 1567 & $1.22(0.07)$ & $0.11(0.09)$ & 0.55 \\
\hline SSB (freq/d) & 2833 & 1266 & $0.57(0.06)$ & $0.02(0.08)$ & 1567 & $0.61(0.06)$ & $0.09(0.08)$ & 0.26 \\
\hline
\end{tabular}

$B M I$ body mass index; $B P$ blood pressure; freq/d frequency per day; SSB sugar sweetened beverages

${ }^{a}$ Weighted mean and standard error (SE) of each variable. Weighted refers to the total number of children within each school. Generalized weighted linear mixed models (GLMM) assessed differences between intervention and control groups

\section{Abbreviations}

RCT: Randomized controlled trial; FV: Fruits and vegetables; BMl: Body mass index; FTS: Farm to School movement; NSLP: National School Lunch Program; SBP: School Breakfast Program; SSBs: Sugar Sweetened Beverages; CCA: Complete case analysis; ACA: Available case analysis; GLC: Garden Leadership Committees

\section{Acknowledgements}

We would like to thank all the children and their families for participating in this study. We would like to thank all of the school stakeholders (i.e., administrators, teachers and staff) for allowing us to teach this program in the schools. We would like to thank the following staff that was instrumental in the implementation of this program: Tatiana Antonio, Bonnie Martin, Shirene Garcia, Michele Hockett Cooper, Hannah Ruisi, Andrea Snow, Liz Metzler, Meg Mattingly, Rachel Hackman, and Cindy Haynie. We would also like to thank Bianca Bidiuc Peterson and Sari Albornoz from the Sustainable Food Center for collaborating with us on this project. We would also like to thank Home Depot for their garden supply donations and attendance at all school garden builds. We would like to thank Lyndsey Waugh and Brandon Lombardi from Sprouts Healthy Communities Foundation for continuing to support our garden-based studies. Finally, we would like to thank all of the University of Texas at Austin undergraduate students for all their hard work helping us collect data, build the gardens, and teach the classes.

\section{Authors' contributions}

JND developed the study design, methodology, secured funding, oversaw data collection, and wrote the first draft of the manuscript. AP and BF performed the data analysis. MJL, SV, RG, AH, MJ, KN were all responsible for data acquisition. DMH, SJP, DR, AEV, KN contributed to study design and securing funding. All authors read, provided feedback, and approved the final submitted version of the manuscript.

\section{Funding}

This clinical study was funded by the National Institutes of Health [1R01HL123865, 2015-2020). Whole Kids Foundation, Home Depot, and Sprouts Healthy Communities Foundation gave funding for garden builds and enhancements. The funders had no role in study design, data collection and analysis, decision to publish, or preparation of the manuscript.
Availability of data and materials

The datasets used in the current study are available from the corresponding author on reasonable request.

Ethics approval and consent to participate

Students and their parents signed assent and consent forms that were approved by the Institutional Review Board (IRB) at UT Austin, IR\#:

2014110045. Clinical trials \# NCT02668744.

\section{Consent for publication}

Not applicable.

\section{Competing interests}

The authors declare that they have no competing interests.

\section{Author details}

${ }^{1}$ Department of Nutritional Sciences, University of Texas at Austin, 1400 Barbara Jordan Blvd, Austin, TX 78723, USA. ${ }^{2}$ Michael \& Susan Dell Center for Healthy Living - Department of Biostatistics and Data Science - The University of Texas Health (UTHealth) Science Center at Houston, Austin Campus, Austin, USA. ${ }^{3}$ Department of Pediatrics, Dell Medical School, University of Texas at Austin, Austin, TX, USA. ${ }^{4}$ Texas A\&M AgriLife Extension Service, Travis County, Austin, USA. ${ }^{5}$ Michael \& Susan Dell Center for Healthy Living - Department of Health Promotion and Behavioral Sciences - UTHealth Science Center at Houston, Austin Campus, Austin, USA.

Received: 2 April 2020 Accepted: 14 January 2021

Published online: 23 January 2021

\section{References}

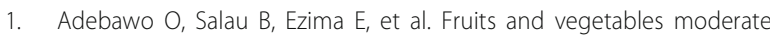
lipid cardiovascular risk factor in hypertensive patients. Lipids Health Dis. $2006 ; 5: 14$

2. Crowe FL, Roddam AW, Key TJ, et al. Fruit and vegetable intake and mortality from ischaemic heart disease: results from the European prospective investigation into Cancer and nutrition (EPIC)-heart study. Eur Heart J. 2011;32(10):1235-43. 
3. Wang X, Ouyang Y, Liu J, et al. Fruit and vegetable consumption and mortality from all causes, cardiovascular disease, and cancer: systematic review and dose-response meta-analysis of prospective cohort studies. BMJ. 2014;349:94490.

4. He K, Hu FB, Colditz GA, Manson JE, Willett WC, Liu S. Changes in intake of fruits and vegetables in relation to risk of obesity and weight gain among middle-aged women. Int J Obes Relat Metab Disord. 2004;28(12):1569-74.

5. Yuan S, Yu HJ, Liu MW, et al. The association of fruit and vegetable consumption with changes in weight and body mass index in Chinese adults: a cohort study. Public Health. 2018;157:121-6.

6. Ledoux TA, Hingle MD, Baranowski T. Relationship of fruit and vegetable intake with adiposity: a systematic review. Obes Rev. 2011;12(5):e143-50.

7. Field AE, Gillman MW, Rosner B, Rockett HR, Colditz GA. Association between fruit and vegetable intake and change in body mass index among a large sample of children and adolescents in the United States. Int J Obes Relat Metab Disord. 2003;27(7):821-6.

8. Wang Y, Ge K, Popkin BM. Why do some overweight children remain overweight, whereas others do not? Public Health Nutr. 2003;6(6):549-58.

9. Kim SA, Moore LV, Galuska D, et al. Vital signs: fruit and vegetable intake among children - United States, 2003-2010. MMWR Morb Mortal Wkly Rep. 2014;63(31):671-6.

10. Drewnowski A, Darmon N. The economics of obesity: dietary energy density and energy cost. Am J Clin Nutr. 2005;82(1 Suppl):265S-73S.

11. Hilmers A, Hilmers DC, Dave J. Neighborhood disparities in access to healthy foods and their effects on environmental justice. Am J Public Health. 2012;102(9):1644-54.

12. Neuhouser ML, Thompson B, Coronado GD, Solomon CC. Higher fat intake and lower fruit and vegetables intakes are associated with greater acculturation among Mexicans living in Washington state. J Am Diet Assoc. 2004;104(1):51-7.

13. Dave JM, Evans AE, Saunders RP, Watkins KW, Pfeiffer KA. Associations among food insecurity, acculturation, demographic factors, and fruit and vegetable intake at home in Hispanic children. J Am Diet Assoc. 2009;109(4): 697-701.

14. Consumer Price Index-all urban consumers. United States Bureau of Labor Statistics. Available from: http://data.bls.gov/PDQ/outside.jsp?survey=cu; last accessed on June 10th, 2020.

15. Anzman-Frasca S, Savage JS, Marini ME, Fisher JO, Birch LL. Repeated exposure and associative conditioning promote preschool children's liking of vegetables. Appetite. 2012;58(2):543-53.

16. Chung LMY, Fong SSM. Appearance alteration of fruits and vegetables to increase their appeal to and consumption by school-age children: a pilot study. Health Psychol Open. 2018;5(2):2055102918802679.

17. Asigbee FM, Davis JN, Markowitz AK, et al. The Association Between Child Cooking Involvement in Food Preparation and Fruit and Vegetable Intake in a Hispanic Youth Population. Curr Dev Nutr. 2020; 4(4). https://doi.org/10.1093/cdn/nzaa028.

18. Lotrean LM, Tutui I. Individual and familial factors associated with fruit and vegetable intake among 11- to 14-year-old Romanian school children. Health Soc Care Community. 2015;23(5):541-9.

19. Berti PR, Krasevec J, FitzGerald S. A review of the effectiveness of agriculture interventions in improving nutrition outcomes. Public Health Nutr. 2004;7(5):599-609.

20. Viola A. Evaluation of the outreach School garden project: building the capacity of two indigenous remote school communities to integrate nutrition into the core school curriculum. Health Promot J Austr. 2006; 17(3):233-9.

21. Morris J, Neustadter A, Zidenberg-Cherr S. First grade gardeners are more likely to taste vegetables. Calif Agric. 2001;55:43-6.

22. Wang M, Rauzon S, Studer N, et al. Exposure to a comprehensive school intervention increases vegetable consumption. J Adolesc Health. 2010;46:1-9.

23. Savoie-Roskos MR, Wengreen $H$, Durward C. Increasing fruit and vegetable intake among children and youth through gardening-based interventions: a systematic review. J Acad Nutr Diet. 2017;117(2):240-50.

24. Lam V, Romses K, Renwick K. Exploring the relationship between school gardens, food literacy and mental well-being in youths using photovoice. Nutrients. 2019;11(6):1354. https://doi.org/10.3390/nu11061354.

25. Park S, AY L, Son K, LEE W, DS K. Gardening interventions for physical and pyschological health benefits in elderly women at community centers. HortTechnology. 2016;26:474-83.
26. Zick CD, Smith KR, Kowaleski-Jones L, Uno C, Merrill BJ. Harvesting more than vegetables: the potential weight control benefits of community gardening. Am J Public Health. 2013;103(6):1110-5.

27. Gatto NM, Martinez LC, Spruijt-Metz D, Davis JN. LA sprouts randomized controlled nutrition, cooking and gardening programme reduces obesity and metabolic risk in Hispanic/Latino youth. Pediatr Obes. 2017;12(1):28-37.

28. Davis J, Nikah K, Asigbee F, et al. Design and participant characteristics of TX sprouts: A school-based cluster randomized gardening, nutrition, and cooking intervention. Contemp Clin Trials doi: 101016/jcct2019105906. 2019.

29. Donner A, Klar N. Design and analysis of cluster randomization trials in health research. New York; 2010.

30. Murray D. Design and analysis of group-randomized trial. New York; 1998

31. Bronfenbrenner U. The ecology of human development: experiments by nature and design. Cambridge: Harvard University Press; 1979.

32. Cicchetti D, Lynch M. Toward an ecological/transactional model of community violence and child maltreatment: consequences for children's development. Psychiatry. 1993;56(1):96-118.

33. Martinez LC, Gatto NM, Spruijt-Metz D, Davis JN. Design and methodology of the LA sprouts nutrition, cooking and gardening program for Latino youth: a randomized controlled intervention. Contemp Clin Trials. 2015;42: 219-27.

34. Extension TAMA. Learn, grow, eat \& Grow! 2014

35. Gatto NM, Ventura EE, Cook LT, Gyllenhammer LE, Davis JN. LA sprouts: a garden-based nutrition intervention pilot program influences motivation and preferences for fruits and vegetables in Latino youth. J Acad Nutr Diet. 2012;112(6):913-20

36. National Center for Health Statistics, Centers for Disease Control and Prevention. 2007-2009. National Health Interview Survey (NHIS). Available at: http://www.cdc.gov/nchs/nhis.htm. Accessed July 1, 2020.

37. Centers for Disease Control and Prevention: CDC growth Charts. Atlanta, GA, U. S. Department of Health and Human Services, Centers for Disease Control and Prevention, National Center for Health Statistics, 2000 (U.S. Publ. no. 314).

38. Penkilo M, George GC, Hoelscher DM. Reproducibility of the School-based nutrition monitoring questionnaire among fourth-grade students in Texas. Nutr Educ Behav. 2008;40(1):20-7.

39. Landry MJ, Ranjit N, Hoelscher DM, et al. Validity and Reliability of an Expanded Vegetable Questionnaire Among Elementary School Children. Curr Dev Nutr. 2019:3(8):nzz080.

40. McHugh ML. Interrater reliability: the kappa statistic. Biochem Med (Zagreb). 2012;22(3):276-82.

41. Portney $L$, Watkins $M$. Foundations of clinical research: application to practice. Upper Saddle River: Prentice Hall Health, 2nd edition; 2000.

42. Thiagarajah K, Fly AD, Hoelscher DM, et al. Validating the food behavior questions from the elementary school SPAN questionnaire. J Nutr Educ Behav. 2008:40(5):305-10.

43. Baranowski T, Davis M, Resnicow K, et al. Gimme 5 fruit, juice, and vegetables for fun and health: outcome evaluation. Health Educ Behav. 2000;27(1):96-111

44. Domel SB, Baranowski T, Davis H, Leonard SB, Riley P, Baranowski J. Measuring fruit and vegetable preferences among 4th- and 5th-grade students. Prev Med. 1993;22(6):866-79.

45. Evans A, Ranjit N, Hoelscher D, et al. Impact of school-based vegetable garden and physical activity coordinated health interventions on weight status and weight-related behaviors of ethnically diverse, low-income students: study design and baseline data of the Texas, grow! Eat! Go! (TGEG) cluster-randomized controlled trial. BMC Public Health. 2016;16:973.

46. Fram MS, Ritchie LD, Rosen N, Frongillo EA. Child experience of food insecurity is associated with child diet and physical activity. J Nutr. 2015; 145(3):499-504.

47. Block $G$, Gillespie $C$, Rosenbaum EH, Jenson C. A rapid food screener to assess fat and fruit and vegetable intake. Am J Prev Med. 2000;18(4):284-8.

48. Harris PA, Taylor R, Thielke R, Payne J, Gonzalez N, Conde JG. Research electronic data capture (REDCap) - A metadata-driven methodology and workflow process for providing translational research informatics support. J Biomed Inform. 2009;42(2):377-81.

49. National Research Council. The prevention and treatment of missing data in clinical trials. Washington, DC: The National Academies Press; 2010.

50. Molenberghs G, Fizmaurice G, Kenward M, Anastasios T, Verbeke G. Handbook of Mlssing Data Methodology; 2014.

51. Holland BS, Copenhaver MD. An improved sequentially Rejective Bonferron test procedure. Biometrics. 1987;43:417-24. 
52. Bacardi-Gascon M, Perez-Morales ME, Jimenez-Cruz A. A six month randomized school intervention and an 18-month follow-up intervention to prevent childhood obesity in Mexican elementary schools. Nutr Hosp. 2012; 27(3):755-62.

53. Epstein LH, Gordy CC, Raynor HA, Beddome M, Kilanowski CK, Paluch R. Increasing fruit and vegetable intake and decreasing fat and sugar intake in families at risk for childhood obesity. Obes Res. 2001;9(3):171-8.

54. Hart CN, Jelalian E, Raynor HA, et al. Early patterns of food intake in an adolescent weight loss trial as predictors of BMI change. Eat Behav. 2010; 11(4):217-22.

55. Coleman KJ, Tiller CL, Sanchez J, et al. Prevention of the epidemic increase in child risk of overweight in low-income schools: the El Paso coordinated approach to child health. Arch Pediatr Adolesc Med. 2005;159(3):217-24.

56. Durant N, Baskin ML, Thomas O, Allison DB. School-based obesity treatment and prevention programs: all in all, just another brick in the wall? Int J Obes. 2008;32(12):1747-51

57. Gonzalez-Suarez C, Worley A, Grimmer-Somers K, Dones V. School-based interventions on childhood obesity: a meta-analysis. Am J Prev Med. 2009; 37(5):418-27.

58. Katz DL, O'Connell M, Njike VY, Yeh MC, Nawaz H. Strategies for the prevention and control of obesity in the school setting: systematic review and meta-analysis. Int J Obes. 2008;32(12):1780-9.

59. Economos CD, Hyatt RR, Goldberg JP, et al. A community intervention reduces $B M I$ z-score in children: shape up Somerville first year results. Obesity (Silver Spring). 2007;15(5):1325-36.

60. Hoelscher DM, Springer AE, Ranjit N, et al. Reductions in child obesity among disadvantaged school children with community involvement: the Travis County CATCH trial. Obesity (Silver Spring). 2010;18(Suppl 1):S36-44.

61. Committee on Accelerating Progress in Obesity Prevention. Food and Nutrition Board; Institute of Medicine. In: Glickman D, Parker L, Sim LJ, Del Valle Cook H, Miller EA, editors. Accelerating Progress in Obesity Prevention: Solving the Weight of the Nation. Washington, DC: National Academies Press; 2012.

62. Hoelscher DM, Kirk S, Ritchie L, Cunningham-Sabo L, Academy PC. Position of the Academy of nutrition and dietetics: interventions for the prevention and treatment of pediatric overweight and obesity. J Acad Nutr Diet. 2013; 113(10):1375-94

63. Lynch BA, Gentile N, Maxson J, Quigg S, Swenson L, Kaufman T. Elementary School-based obesity intervention using an educational curriculum. J Prim Care Community Health. 2016;7(4):265-71.

64. Pearson N, Biddle SJ, Gorely T. Family correlates of fruit and vegetable consumption in children and adolescents: a systematic review. Public Health Nutr. 2009;12(2):267-83.

65. Amuta AO, Jacobs W, Idoko EE, Barry AE, McKyer EL. Influence of the home food environment on Children's fruit and vegetable consumption: a study of rural low-income families. Health Promot Pract. 2015;16(5):689-98.

66. Paineau $\mathrm{DL}$, Beaufils $\mathrm{F}$, Boulier $\mathrm{A}$, et al. Family dietary coaching to improve nutritional intakes and body weight control: a randomized controlled trial. Arch Pediatr Adolesc Med. 2008;162(1):34-43.

67. Funderburk K, Struempler B, Parmer SM, Griffin JB. Body quest parent: a text message parent education intervention to supplement a School-based obesity prevention initiative for third-graders. J Nutr Educ Behav. 2018;50(4): 415-7 e411.

68. Zarnowiecki D, Mauch CE, Middleton G, et al. A systematic evaluation of digital nutrition promotion websites and apps for supporting parents to influence children's nutrition. Int J Behav Nutr Phys Act. 2020;17(1):17.

69. Trevino RP, Yin Z, Hernandez A, Hale DE, Garcia OA, Mobley C. Impact of the Bienestar school-based diabetes mellitus prevention program on fasting capillary glucose levels: a randomized controlled trial. Arch Pediatr Adolesc Med. 2004;158(9):911-7.

70. Epstein LH, Valoski A, Wing RR, McCurley J. Ten-year outcomes of behavioral family-based treatment for childhood obesity. Health Psychol. 1994;13(5): 373-83.

71. Berge JM, Everts JC. Family-based interventions targeting childhood obesity: a meta-analysis. Child Obes. 2011;7(2):110-21.

72. Cook LT, O'Reilly GA, Goran MI, Weigensberg MJ, Spruijt-Metz D, Davis JN. Vegetable consumption is linked to decreased visceral and liver fat and improved insulin resistance in overweight latino youth. J Acad Nutr Diet. 2014;114(11):1776-83. https://doi.org/10.1016/j.jand.2014.01.017.
73. Tang GY, Meng X, Li Y, Zhao CN, Liu Q, Li HB. Effects of vegetables on cardiovascular diseases and related mechanisms. Nutrients. 2017;9(8):857. https://doi.org/10.3390/nu9080857.

74. Bradbury KE, Appleby PN, Key TJ. Fruit, vegetable, and fiber intake in relation to cancer risk: findings from the European prospective investigation into Cancer and nutrition (EPIC). Am J Clin Nutr. 2014;100(Suppl 1):394S-8S.

75. Whole School WC, Whole Child. Association for Supervision and Curriculum Development (ASCD).http://www.ascd.org/programs/learning-and-health/ wscc-model.aspx. last assess on March 3rd, 2020

76. Centers for Disease Control and Prevention. National Health Education Standards. Retrieved https://www.cdc.gov/healthyschools/sher/standards/ index.htm.last. Accessed 10 Jan 2020

77. Robinson-O'Brien R, Burgess-Champoux T, Haines J, Hannan PJ, NeumarkSztainer D. Associations between school meals offered through the National School Lunch Program and the School breakfast program and fruit and vegetable intake among ethnically diverse, low-income children. J Sch Health. 2010:80(10):487-92.

78. Cullen KW, Chen TA, Dave JM. Changes in foods selected and consumed after implementation of the new National School Lunch Program meal patterns in Southeast Texas. Prev Med Rep. 2015;2:440-3.

79. Gearan EC, Fox MK. Updated nutrition standards have significantly improved the nutritional quality of School lunches and breakfasts. J Acad Nutr Diet. 2020;120(3):363-70.

\section{Publisher's Note}

Springer Nature remains neutral with regard to jurisdictional claims in published maps and institutional affiliations.
Ready to submit your research? Choose BMC and benefit from:

- fast, convenient online submission

- thorough peer review by experienced researchers in your field

- rapid publication on acceptance

- support for research data, including large and complex data types

- gold Open Access which fosters wider collaboration and increased citations

- maximum visibility for your research: over $100 \mathrm{M}$ website views per year

At BMC, research is always in progress.

Learn more biomedcentral.com/submissions 